\title{
Phase-Contrast Microscopy
}

National Cancer Institute

\section{Source}

National Cancer Institute. Phase-Contrast Microscopy. NCI Thesaurus. Code C16857.

A simple non-quantitative form of interference microscopy of great utility in visualising live cells. Small differences in optical path length due to differences in refractive index and thickness of structures are visualised as differences in light intensity. 